UNIVERSIDADE DE SÃO PAULO

INSTITUTO DE BIOCIÊNCIAS

PROGRAMA DE PÓS-GRADUAÇÃO EM CIÊNCIAS BIOLÓGICAS (BOTÂNICA)

FREDERICO ROCHA RODRIGUES ALVES

\title{
MANIPULAÇÃO DE FITOCROMOS COMO ESTRATÉGIA DE BIOFORTIFICAÇÃO DE FRUTOS DE TOMATEIRO (Solanum lycopersicum L.)
}

PHYTOCHROME MANIPULATION AS A BIOFORTIFICATION STRATEGY OF TOMATO FRUITS (Solanum lycopersicum L.) 


\title{
MANIPULAÇÃO DE FITOCROMOS COMO ESTRATÉGIA DE BIOFORTIFICAÇÃO DE FRUTOS DE TOMATEIRO (Solanum Iycopersicum L.)
}

\author{
PHYTOCHROME MANIPULATION AS A BIOFORTIFICATION STRATEGY OF \\ TOMATO FRUITS (Solanum lycopersicum L.)
}

\begin{abstract}
Tese apresentada ao Instituto de Biociências da Universidade de São Paulo para a obtenção do título de Doutor em Ciências (Área Botânica)

Orientador: Prof. Dr. Luciano Freschi
\end{abstract}


Alves, Frederico Rocha Rodrigues

Manipulação de fitocromos como estratégia de biofortificação de frutos de tomateiro (Solanum lycopersicum L.). / Frederico Rocha Rodrigues Alves; orientador Luciano Freschi. -- São Paulo, 2019.

117 f. + anexo

Tese (Doutorado) - Instituto de Biociências da Universidade de São Paulo, Departamento de Botânica.

1. fotobiotecnologia. 2. metabolismo secundário. 3. antioxidantes. 4. carotenoides. 5. tocoferois. I. Freschi, Luciano, orient. II. Título.

\section{COMISSÃO JULGADORA}

$\operatorname{Prof(a).~Dr(a).~}$

$\operatorname{Prof}(a) . \operatorname{Dr}(a)$.

$\operatorname{Prof(a).~Dr(a).~}$ 
As informações científicas aqui contidas somente foram possíveis de serem descritas graças às valiosas contribuições de diversas pessoas e instituições durante este período de aperfeiçoamento pessoal e profissional. A todas elas dedico algumas palavras como sinceros agradecimentos.

À minha família: minha mãe, Maria de Lourdes, ao meu pai, Erivaldo, e ao meu irmão, Guilherme, por serem minha fonte incondicional de amor, carinho e apoio em todos os momentos. Obrigado por nunca terem deixado de apostar na Educação como elemento transformador de nossas vidas. Espero que vocês tenham orgulho de mais essa conquista para nossa família. Calma, mãe, logo logo já estarei voltando com mais um diploma para casa. <3

À Universidade Federal de Goiás, cujo envolvimento em minha vida se iniciou desde a creche universitária. Meus agradecimentos especiais ao corpo docente e técnico do Departamento de Botânica do Instituto de Ciências Biológicas da UFG por terem aceitado o meu pedido de afastamento para o Doutorado e suprido a ausência de um técnico de laboratório para que ele pudesse se capacitar.

Ao Carlos Plasenzotti, por todo o amor, companheirismo e inestimável apoio. Você vivenciou todo o período desse Doutorado! Agora você sabe um pouco mais sobre fitocromos!! YAY!!! Gracias, duraznito!

Aos meus velhos amigos goianienses, sempre a minha pedra de apoio nos momentos de fuga e recarga. Amo vocês, Allisson Takuya, Guilherme Tristão, Kamilla Leonel, Jean Hita, Amanda Hita, Lara Medeiros, Carol \#, Wagner Kaco, Antônio Octávio e Carol Kovacs.

Aos meus novos amigos que me acolheram, me suportaram e me incentivaram durante todo o período do Doutorado. From here to eternity!!! À Priscila "Mas eu sou um neném" Bittencourt, Ricardo “Grilo" Bianchetti, Filipe "Pipe" Pikart, Giovanni “Jof” Cerruti, Bruno Gobara, Daniele “HY-5!!!” Rosado, Rafael Zuccarelli, Alejandra Matiz, Leyde Nayane, Bruno Lira e Paulo Mioto. Terei sempre comigo inestimáveis recordações de cada um de vocês.

A todos os alunos dos Laboratórios de Fisiologia do Desenvolvimento Vegetal e Genética Molecular de Plantas. Obrigado pelas valiosas trocas de informações, debate de ideias, contribuições e colaborações nos experimentos.

Aos meus colegas laboratoristas Aline Bertinatto, Ana Maria Rodrigues, William Oliveira e Silvia Blanco por todo o imensurável suporte técnico e material que permitiram o bom andamento das pesquisas. Estendo os agradecimentos a todo 0 corpo de funcionários do Departamento de Botânica do IB/USP. 
A todos os professores que contribuíram com os seus ensinamentos e experiência para a construção desta tese. Em especial, meus agradecimentos à Dra. Magdalena Rossi, Dra. Cláudia Furlan, Dr. Eduardo Purgatto e Dr. Diego Demarco.

Ao Prof. Dr. Luciano Freschi, meu prezado orientador, obrigado pela confiança depositada em mim, aos seus ensinamentos e à sua disponibilidade durante o desenvolvimento e execução das pesquisas. Eu ainda guardo o rascunho que você fez sobre um vetor de sobre-expressão, desenhado em julho de 2015, quando você aceitou conversar com um rapaz que ainda não tinha tido nenhuma experiência prática em biologia molecular. E olhem só para essa tese! Mais uma vez, muito obrigado pela sua determinante contribuição no meu desenvolvimento científico. Abs, Luciano.

À Fundação de Amparo à Pesquisa do Estado de São Paulo (FAPESP) e à Coordenação de Aperfeiçoamento de Pessoal de Nível Superior (CAPES) pela concessão dos apoios acadêmico e financeiro, imprescindíveis para a realização do projeto.

At.te, $\mathrm{F}$ 
"Feliz aquele que transfere o que sabe e aprende o que ensina."

Cora Coralina (1889-1985)

Art. 205. A educação, direito de todos e dever do Estado e da família, será promovida e incentivada com a colaboração da sociedade, visando ao pleno desenvolvimento da pessoa, seu preparo para o exercício da cidadania e sua qualificação para o trabalho.

- Constituição da República Federativa do Brasil, 1988 
ÍNDICE

$\begin{array}{ll}\text { RESUMO } & 8\end{array}$

$\begin{array}{ll}\text { ABSTRACT } & 9\end{array}$

$\begin{array}{ll}\text { REFERENCIAL TEÓRICO } & 10\end{array}$

O tomate como alvo de manipulação biotecnológica 10

A transdução do sinal luminoso pelo fitocromos 13

A influência da luz e do fitocromo na síntese de metabólitos de valor $\begin{array}{ll}\text { nutricional em frutos de tomateiro } & 19\end{array}$

$\begin{array}{ll}\text { Referências } & 24\end{array}$

OBJETIVOS 35

CAPÍTULO ÚNICO: Beyond the limits of photoperception: constitutively active PHYTOCHROME B2 overexpression as a strategy of tomato biofortification

$\begin{array}{ll}\text { SUMMARY } & 36\end{array}$

$\begin{array}{ll}\text { INTRODUCTION } & 37\end{array}$

$\begin{array}{ll}\text { RESULTS } & 39\end{array}$

$\begin{array}{ll}\text { DISCUSSION } & 57\end{array}$

$\begin{array}{ll}\text { EXPERIMENTAL PROCEDURES } & 64\end{array}$

$\begin{array}{ll}\text { SUPPORTING INFORMATION } & 70\end{array}$

$\begin{array}{lr}\text { REFERENCES } & 99\end{array}$

$\begin{array}{ll}\text { CONSIDERAÇÕES FINAIS } & 114\end{array}$

PRODUÇÃO CIENTÍFICA E ACADÊMICA NO PERÍODO 116 
ALVES, Frederico Rocha Rodrigues. Manipulação de fitocromos como estratégia de biofortificação de frutos de tomateiro (Solanum lycopersicum L.). 2019. 117f. Tese (Doutorado em Ciências Biológicas - Área Botânica) - Instituto de Biociências, Universidade de São Paulo, São Paulo, Brasil.

A manipulação de elementos da cadeia de sinalização luminosa tem sido amplamente empregada como estratégia de melhoramento de plantas de interesse agronômico. Os fitocromos (PHYs), fotorreceptores de luz vermelha/vermelha-distante, possuem papéis centrais na transdução do sinal luminoso controlando diversos processos fisiológicos em frutos, inclusive aqueles relacionados com a síntese de compostos de valor nutricional. Entretanto, informações a respeito da possibilidade de aplicação da manipulação de PHYs como ferramenta fotobiotecnológica visando a biofortificação de frutos ainda são limitadas. Nesta tese, os impactos da sobre-expressão fruto-específica de PHYTOCHROME B2 ( $P H Y B 2$ ) e de uma forma mutante constitutivamente ativa desse fotorreceptor ( $P H Y B 2^{Y 252 H}$ ) sobre o desenvolvimento de frutos de tomateiro foram avaliados. Em frutos verdes, tanto a sobre-expressão de PHYB2 quanto de $P H Y B 2^{Y 252 H}$ aumentou o número de plastídios e o desenvolvimento de tilacoides, incrementando a capacidade de síntese e estocagem de importantes compostos de valor nutricional. Além disso, os frutos transgênicos maduros sobreexpressando $\mathrm{PHYB2}^{\mathrm{Y} 252 \mathrm{H}}$ acumularam maior conteúdo de carotenoides, vitamina $\mathrm{E}$, flavonoides e vitamina $C$, estando esse fenótipo associado a modulações específicas na transcrição de genes biossintéticos das respectivas rotas metabólicas ao longo do desenvolvimento do fruto. Comparados ao tipo selvagem, os frutos transgênicos apresentaram limitadas alterações em seu metabolismo primário, com destaque para o aumento e diminuição nos teores de compostos lipídicos e açúcares solúveis, respectivamente. O acúmulo de compostos antioxidantes foi substancialmente intensificado pela sobre-expressão de

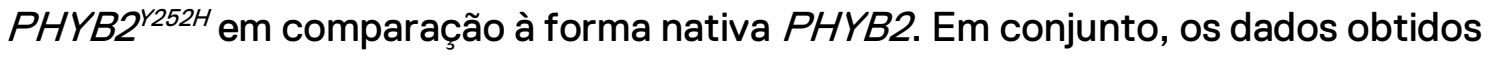
indicam que a manipulação da atividade de PHYs constitui uma relevante ferramenta de fotobiotecnologia para a biofortificação de frutos carnosos.

Palavras-chave: fotobiotecnologia, metabolismo secundário, antioxidantes, carotenoides, tocoferois, flavonoides, ascorbato. 
ALVES, Frederico Rocha Rodrigues. Phytochrome manipulation as a biofortification strategy of tomato fruits (Solanum lycopersicum L.). 2019. 117p. Thesis (Ph.D. in Biological Sciences - Botany) - Instituto de Biociências, Universidade de São Paulo, São Paulo, Brazil.

Manipulation of light signaling pathway components has been widely applied as a molecular plant breeding strategy in crop species. Phytochromes (PHYs), $\mathrm{red} /$ far-red photoreceptors, play central roles concerning light signal transduction, controlling a plethora of physiological processes in fruits, including the biosynthesis of compounds with nutritional value. However, information regarding the applicability of PHY manipulation as a photobiotechnological tool aiming fruit biofortification are limited. In the present thesis, the impacts of fruit-specific overexpression of PHYTOCHROME B2 (PHYB2) and a mutated constitutively active form of this photoreceptor $\left(P H Y B 2^{Y 252 H}\right)$ on tomato fruit development were evaluated. In green fruits, either $P H Y B 2$ or $P H Y B 2^{Y 252 H}$ overexpression increased plastid number and thylakoid development, boosting up the synthesis and storage capacities of important compounds with nutritional value. Accordingly, red ripe $P H Y B 2^{Y 252 H}$-overexpressing fruits accumulated more carotenoids, vitamin $\mathrm{E}$, flavonoids and vitamin $C$ as a consequence of specific modulation of biosynthetic genes associated with the respective metabolic pathways throughout fruit development. Compared to the wildtype, transgenic fruits exhibited limited changes in primary metabolism, including increments and reductions in lipid and soluble sugar levels, respectively. Accumulation of antioxidant compounds was substantially intensified by $\mathrm{PHYB} 2^{\mathrm{Y} 252 \mathrm{H}}$-overexpression compared to the native form PHYB2. Altogether, our findings indicate that PHY activity manipulation represents a relevant photobiotechnological tool for fleshy fruit biofortification.

Keywords: photobiotechnology, secondary metabolism, antioxidants, carotenoids, tocopherols, flavonoids, ascorbate. 


\section{O tomate como alvo de manipulação fotobiotecnológica}

O fruto do tomateiro está entre os alimentos mais consumidos no mundo, seja in natura ou processado na forma de molhos e sucos, e tanto a sua produção quanto a área mundial dedicada ao seu cultivo mais que dobrou nos últimos 20 anos (Bergougnoux, 2014). O tomate possui grande importância na alimentação humana devido ao seu alto valor nutricional, associado especialmente aos seus elevados teores de antioxidantes.

O licopeno é um dos principais antioxidantes com ação sobre o corpo humano, desempenhando papel crítico no combate aos radicais livres e na prevenção de diversas doenças e, em termos mundiais, o tomate constitui a principal fonte desse composto nutracêutico para o homem (Khachik et al., 2002). Aumentos no consumo de licopeno estão associados à prevenção de doenças cardiovasculares, hepáticas e do sistema nervoso central, além de alguns tipos de câncer como o de próstata e do trato digestivo (Heber \& Lu, 2002; Stice et al., 2018). O licopeno é responsável pela coloração avermelhada dos frutos e é o carotenoide presente em maior concentração no tomate.

O segundo carotenoide mais abundantemente encontrado no tomate é o $\beta$ caroteno, precursor da vitamina A, relacionado com a saúde dos olhos e proteção da pele (Grune et al., 2010), cuja deficiência é um dos principais problemas nutricionais que afetam crianças e mulheres grávidas especialmente em países em desenvolvimento (West et al., 2002).

Além dos carotenoides, teores significativos de tocoferóis (vitamina E), flavonoides e ácido ascórbico (vitamina C) também podem ser encontrados em frutos maduros de tomate, os quais são igualmente benéficos para a saúde humana, possuindo propriedades antioxidantes e anti-carcinogênicas (Dorais et al., 2008). Os flavonoides e o ácido ascórbico, por exemplo, são antioxidantes hidrofílicos que complementam a natureza hidrofóbica dos carotenoides e tocoferois. Dietas ricas 
em diversas classes de antioxidantes têm sido associadas à redução nos riscos de doenças cardíacas, certos tipos de câncer e outras doenças degenerativas relacionadas ao envelhecimento (Wilson et al., 2017).

O valor econômico e as propriedades nutricionais atribuídas aos frutos de tomateiro fazem desta espécie um importante alvo para biofortificação, ou seja, o emprego de estratégias para aumentar o conteúdo nutricional tanto por métodos tradicionais de melhoramento genético quanto por manipulações via técnicas de transgenia (Garg et al., 2018; Martin et al., 2011).

O aumento na concentração de compostos nutracêuticos tem sido buscado através da modulação da expressão de genes que codificam enzimas envolvidas nas rotas biossintéticas específicas desses compostos ou fatores de transcrição envolvidos na regulação de tais enzimas (Bovy et al., 2007; Butelli et al., 2008). Por exemplo, várias tentativas têm sido realizadas com o intuito de aumentar o conteúdo de carotenoides em frutos de tomate utilizando genes bacterianos que codificam enzimas envolvidas na biossíntese destas substâncias (Fraser et al., 2001; Römer et al., 2000). Estas abordagens normalmente resultam no incremento dos teores de um ou poucos metabólitos, sem desencadear elevações no fluxo através de toda a rota biossintética desses compostos.

De forma semelhante, os níveis de flavonoides e vitamina $\mathrm{C}$ em tomate têm sido aumentados tanto pela modulação direta de genes envolvidos em etapas biossintéticas (Li et al., 2019; Muir et al., 2001) quanto por meio de fatores de transcrição relacionados ao controle das rotas bioquímicas (Bovy et al., 2002; Xu et al., 2015a). Embora ambas estratégias tenham sido efetivas na elevação do conteúdo de flavonoides, raramente os teores de carotenoides em frutos dessas linhagens foram alterados. Assim sendo, a sobre-expressão de genes que codificam enzimas biossintéticas geralmente resulta em tomates com conteúdo aumentado específico para apenas uma classe de metabólitos.

Uma das alternativas para a obtenção de aumentos simultâneos em diversos metabólitos nutracêuticos é a modulação de genes regulatórios cujos produtos influenciam simultaneamente as rotas de biossíntese das diferentes classes de 
compostos de interesse, mesmo que essas rotas sejam relativamente independentes. Estes genes, frequentemente são oriundos das próprias plantas e consequentemente, este método seria mais facilmente aceito pelo público consumidor dos produtos. Uma abordagem capaz de produzir aumentos concomitantes em diversas classes de compostos nutracêuticos consiste na modulação de fatores associados à percepção ou transdução do sinal luminoso (Azari et al., 2010a; Wang et al., 2008).

As plantas são capazes de perceber a luz por meio dos fotorreceptores, que atuam integrando os sinais luminosos do ambiente externo ao ambiente celular interno. Os diversos fotorreceptores desempenham papel central no ajuste e na integração da sinalização da luz para o crescimento, desenvolvimento, sobrevivência e reprodução, controlando processos diversos tais como a fotossíntese, germinação, floração, fototropismos e estabelecimento e manutenção de ritmos circadianos (Jiao et al., 2007; Quail, 2002).

Os fotorreceptores possuem um módulo fotossensor, responsável pela absorção da luz por moléculas específicas denominadas cromóforos, e um módulo efetor que exerce a atividade biológica, por exemplo, catálise e/ou interação com outra proteína (Ziegler \& Möglich, 2015). De uma maneira geral, as fotoisomerizações que ocorrem nos cromóforos após a absorção de luz no comprimento de onda adequado fazem com que os fotorreceptores sejam capazes de interagir com proteínas sinalizadoras e/ou fatores transcrição que levarão à alteração no padrão de expressão de genes relacionados à resposta luminosa. Consequentemente, não é motivo de surpresa que mutações em genes relacionados à percepção ou transdução do sinal luminoso resultem em alterações profundas nos perfis de expressão gênica com efeitos marcantes no crescimento, desenvolvimento e metabolismo vegetal (Jiao et al., 2007; Kolotilin et al., 2007). Tais fatores podem, portanto, representar alvos genéticos prioritários para o incremento da qualidade dos frutos tanto por abordagens clássicas de melhoramento genético quanto por técnicas de transgenia.

Os estudos realizados até o momento dentro desta concepção vêm apresentando resultados promissores (Azari et al., 2010a; Azari et al., 2010b; 
Davuluri et al., 2005; Kolotilin et al., 2007; Liu et al., 2004; Wang et al., 2008) e, portanto, um crescente interesse da comunidade científica tem sido despertado no que concerne à identificação, análise e modulação de elementos envolvidos na transdução do sinal luminoso a fim de se utilizar ao máximo o impacto de tal estratégia fotobiotecnológica (Ganesan et al., 2017; Gururani et al., 2015). Adicionalmente, a maioria dos genes que codificam fatores relacionados à transdução dos sinais luminosos são altamente conservados dentro do reino vegetal e desta forma, parece provável que seus efeitos sejam reprodutíveis em diversas espécies vegetais de interesse agronômico (Azari et al., 2010a).

Apesar desse considerável potencial biotecnológico e do fato que as primeiras constatações do papel estimulatório da luz sobre o conteúdo de fitonutrientes em frutos de tomate terem sido obtidas há mais de 70 anos (Piringer \& Heinze, 1954), apenas recentemente alguns avanços foram obtidos no que tange ao conhecimento da relação entre a percepção e transdução do sinal luminoso e a concentração de compostos nutracêuticos em tomate e outros frutos carnosos.

\section{A transdução do sinal luminoso pelos fitocromos}

O fitocromo foi o primeiro dos fotorreceptores a ser identificado através de pesquisas envolvendo o efeito da luz vermelha e vermelho-distante sobre a germinação de sementes de alface (Borthwick et al., 1954). Nestes estudos iniciais, o fitocromo foi identificado e caracterizado como sendo uma cromoproteína fotorreversível: sua forma biologicamente inativa Fv absorve a luz em comprimentos de onda na região do vermelho ( $\lambda$ entre 650 e $670 \mathrm{~nm}$ ) e se converte na forma ativa Fvd, que, por sua vez, é capaz de absorver a luz na região do vermelho-distante ( $\lambda$ entre 705 e $730 \mathrm{~nm}$ ) e retornar à sua forma inicial Fv. Em condições de escuro, Fvd também é convertida em Fv (Borthwick, 1957; Borthwick \& Hendricks, 1960; Borthwick et al., 1952; Butler et al., 1959). 
O fitocromo é formado pela dimerização de duas subunidades proteicas. Cada um dos monômeros é composto por uma molécula de pigmento denominada cromóforo, responsável pela absorção de luz, e uma cadeia polipeptídica chamada apoproteína. Nas plantas superiores, o cromóforo do fitocromo é um tetrapirrol linear denominado fitocromobilina, sintetizado nos plastídios. Ao ser exportada do plastídio para o citosol, a fitocromobilina se liga à apoproteína de forma autocatalítica por meio de uma ligação tioéster a um resíduo de cisteína, formando a holoproteína (Kevei et al., 2007; Li \& Lagarias, 1992; Rockwell et al., 2006).

As apoproteínas PHY são codificadas por uma pequena família de genes nas angiospermas. Por exemplo, Arabidopsis contem cinco genes PHY (PHYA a PHYE), a mesma quantidade em tomateiro (PHYA, PHYB1, PHYB2, PHYE e PHYF), enquanto o arroz possui apenas três (PHYA a PHYC) (Bae \& Choi, 2008; Clack et al., 1994; Hauser et al., 1995; Sharrock \& Quail, 1989). Devido a isso, os diferentes fitocromos apresentam propriedades moleculares distintas e podem agir isoladamente ou em conjunto na determinação das diversas respostas dependentes de luz, apresentando funções semelhantes ou diferentes nas plantas (Bae \& Choi, 2008).

Estruturalmente, os fitocromos são organizados em dois módulos: a porção $\mathrm{N}$-terminal fotossensora e a porção C-terminal efetora, conectadas por uma região de dobradiça flexível. Cada módulo é constituído por determinados domínios. O módulo fotossensor consiste dos domínios P1/NTE (extensão Nterminal), P2/PAS (Per/Arnt/Sim), P3/GAF (cGMP fosfodiesterase/Adenilciclase/FhIA) e P4/PHY (fitocromo-específico) (Figura R1). O resíduo conservado de cisteína ao qual o cromóforo fitocromobilina se encontra covalentemente ligado se encontra no domínio GAF (Wagner et al., 2005). Recentemente, a estrutura do módulo fotossensor de PHYB foi melhor elucidada (Burgie et al., 2014; Von Horsten et al., 2016), demonstrando duas conformações interessantes: o motivo do laço com nó sensor de luz entre os domínios PAS e GAF, responsável pela estabilidade entre os domínios durante a fotoconversão Fv-Fvd e interação com determinados fatores de transcrição (Kikis et al., 2009); e o motivo da língua no dominío PHY, que medeia a associação com 
o módulo efetor durante a fotoconversão (Burgie et al., 2017). O módulo efetor Cterminal consiste em um domínio PRD (domínio relacionado ao PAS) composto por um par de repetições (PAS-A e PAS-B) e um domínio HKRD (semelhante à histidina cinase). As funções do módulo efetor estão relacionadas à dimerização dos fitocromos, localização nuclear e interação proteína-proteína com alguns componentes da cadeia de sinalização (Bae \& Choi, 2008; Klose et al., 2015; Pham et al., 2018; Qiu et al., 2017).

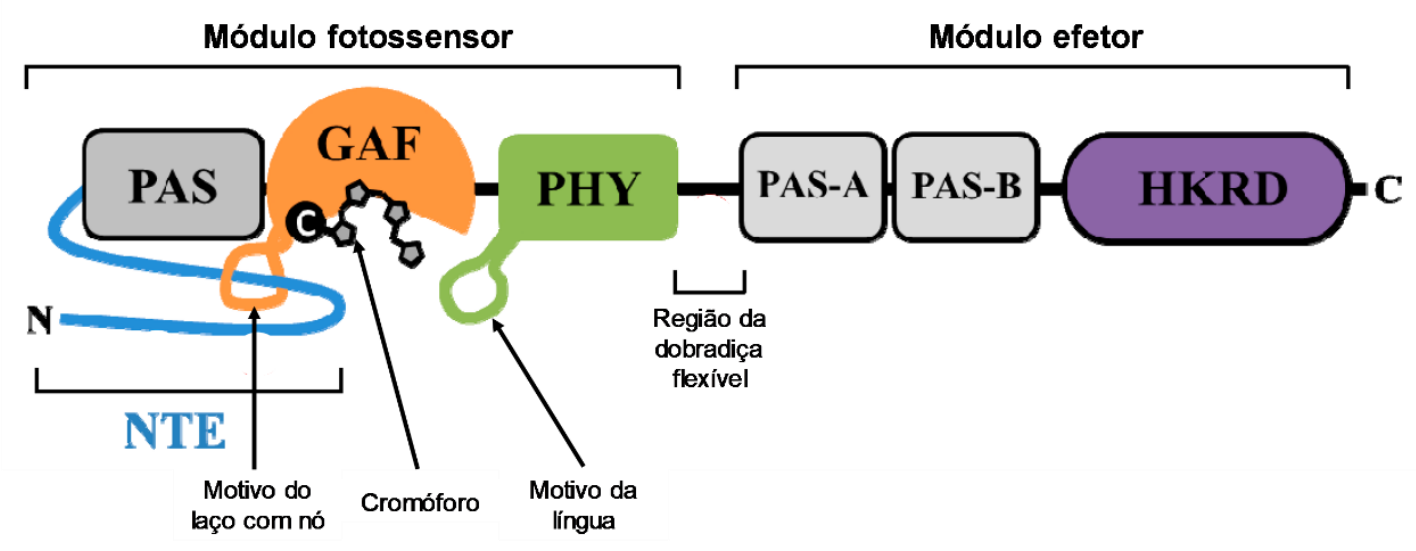

Figura R1. Esquema da estrutura do fitocromo e identificação dos seus domínios constituintes. Abreviações dos domínios se encontram descritas no texto. Adaptado de Hoang et al. (2019).

Em síntese, a sinalização luminosa dependente de fitocromos segue os seguintes passos: fotoativação, translocação para o núcleo, interação com outras proteínas, transdução do sinal (mudanças nos níveis dos fatores de transcrição, por exemplo) e controle transcricional dos genes fotorresponsivos (Xu et al., 2015b).

No citosol, o fitocromo se encontra dimerizado em seu estado inativo Fv. A absorção de luz vermelha pela fitocromobilina em sua forma inativa Fv resulta na fotoisomerização cis para trans da dupla ligação dos carbonos entre os anéis $\mathrm{C}$ e D do cromóforo acompanhada de uma rotação do anel D (Hughes, 2010; Yang et al., 2014). Essa importante alteração estrutural desencadeia mudanças nas interações intermoleculares da proteína que levam à conformação ativa Fvd, translocada para o núcleo (Chen et al., 2005; Fankhauser \& Chen, 2008). Os 
fitocromos, porém, não possuem sinais de localização nuclear (SLNs) endógenos ativos e, portanto, alguns facilitadores de transporte que possuem SLNs precisam ser recrutados para a translocação. Para PHYA, as proteínas FAR-RED ELONGATED HYPOCOTYL 1 (FHY1) e FHY1-LIKE (FHL) interagem com as proteínas fotoativadas e o complexo formado é importado para o núcleo (Hiltbrunner et al., 2006). Para os demais fitocromos (PHYB-PHYE), proteínas facilitadoras semelhantes ainda não foram identificadas e se hipotetiza de que fatores de transcrição envolvidos em sua rota de sinalização sejam mediadores de sua translocação para o núcleo (Pfeiffer et al., 2012).

No núcleo, os fitocromos interagem e inibem duas classes principais de repressores de respostas fotomorfogênicas: o complexo formado pelas proteínas CONSTITUTIVE PHOTOMORPHOGENESIS $\mathrm{e}$ SUPPRESSOR OF PHYA (COP1/SPA), atuando na degradação mediada por ubiquitina de fatores relacionados à sinalização luminosa (Podolec \& Ulm, 2018) e as proteínas PHYTOCHROME INTERACTING FACTORS (PIFs), atuando sobre a transcrição de genes responsivos à luz (Leivar \& Quail, 2011).

O mecanismo de proteólise envolve a ligação covalente de uma proteína ubiquitina ao seu substrato, com as atividades sequenciais de uma enzima ativadora da ubiquitina (E1), uma enzima conjugadora da ubiquitina (E2) e uma ubiquitina ligase (E3), levando à degradação do substrato pelo proteassomo 26S (Pickart 2001). A enzima ubiquitina ligase E3 determina a especificidade do substrato a ser degradado. COP1 é uma ligase E3, interagindo com SPA na repressão da fotomorfogênese. O complexo COP1-SPA interage com múltiplos fatores de transcrição chaves para respostas fotomorfogênicas, marcando-os por ubiquitinação para degradação no proteossomo (Podolec \& Ulm, 2018). Alvo da ação desse complexo repressor, LONG HYPOCOTYL 5 (HY5) é um dos fatores de transcrição centrais da sinalização luminosa, se ligando a vários promotores de genes responsivos à luz, promovendo a sua expressão e o desenvolvimento fotomorfogênico (Gangappa \& Botto, 2016). PHYs interagem com o complexo COP1-SPA, dissociando-os e fazendo com que COP1 seja transportado para fora do núcleo, permitindo o acúmulo da proteína HY5 (Lu et al., 2015). 
Em contrapartida, as PIFs são fatores de transcrição principalmente associados com a regulação dos genes responsáveis pelas respostas de desenvolvimento em condições de ausência de luz (escotomorfogênese), caracterizado por indução do alongamento celular e inibição da síntese de pigmentos fotossintéticos (Leivar \& Monte, 2014). Com a translocação dos fitocromos para o núcleo após estímulo luminoso, PHYs interagem com PIFs, sendo fosforiladas, ubiquitinadas e degradadas pelo proteassomo 265 (Leivar \& Quail, 2011; Shen et al., 2008). A representação das interações dos fitocromos com as proteínas PIFs e o complexo COP1/SPA regulando a transcrição de genes responsivos à luz está indicada na Figura R2.
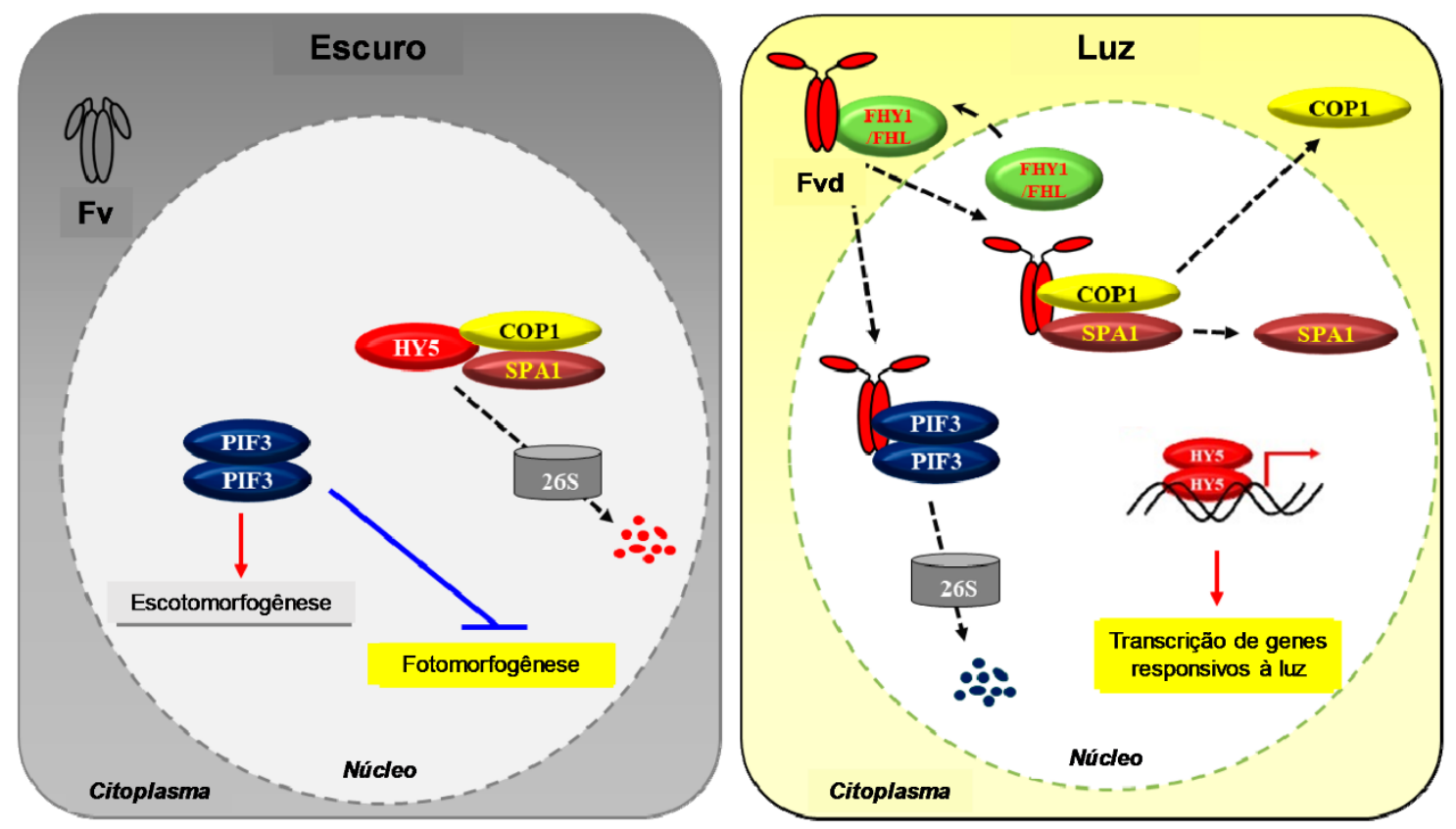

Figura R2. Modelo simplificado de sinalização do sinal luminoso dependente de fitocromos. $\mathrm{Na}$ ausência de luz, as proteínas PIFs induzem a expressão de genes responsáveis pelo desenvolvimento escotomorfogênico e as proteínas HY5, fatores de transcrição de genes responsivos à luz, são ubiquitinadas e degradadas por ação do complexo COP/SPA. Sob iluminação e fotoativação do fitocromo, a forma ativa Fvd é translocada para o núcleo, marcando as proteínas PIFs para degradação pelo proteassomo $26 \mathrm{~S}$ e dissociando o complexo COP/SPA. HY5, dessa forma, se encontra livre para induzir a transcrição de genes fotomorfogênicos. Abreviações das proteínas se encontram descritas no texto. Adaptado de Hoang et al. (2019). 
Os mecanismos moleculares pelos quais os PHYs dissociam o complexo COP1-SPA e também fosforilam PIFs ainda não estão bem elucidados (Hoang et al., 2019; Pham et al., 2018).

Assim sendo, o fitocromo atua como um interruptor ativado por luz vermelha, a depender do balanço entre suas formas ativa e inativa, para realizar alterações na transcrição de genes por meio da sua interação com componentes da rota de sinalização luminosa. Porém, certas mutações que resultam em mudanças conformacionais dos fitocromos podem alterar a sua atividade e sua sensibilidade ao sinal luminoso para a fotoativação.

Em Arabidopsis, mutações na porção N-terminal dos fitocromos foram mapeadas e envolvem deficiência na incorporação do cromóforo, na estabilização da forma ativa Fvd ou na transdução do sinal (Nagatani 2010; Rockwell \& Lagarias, 2006). Algumas mutações de ganho de função também foram encontradas no domínio GAF, promovendo tanto maior estabilidade da proteína (PHYA ${ }^{\mathrm{E} 229 \mathrm{~K}}$ ) (Dieterle et al., 2005) ou até mesmo respostas constitutivas independentes do sinal luminoso (PHYB ${ }^{\mathrm{Y} 26 \mathrm{H}}$ ) (Hu et al., 2009; Su \& Lagarias, 2007). Um resumo das mutações mapeadas no domínio fotossensor dos fitocromos está detalhada na Figura R3.

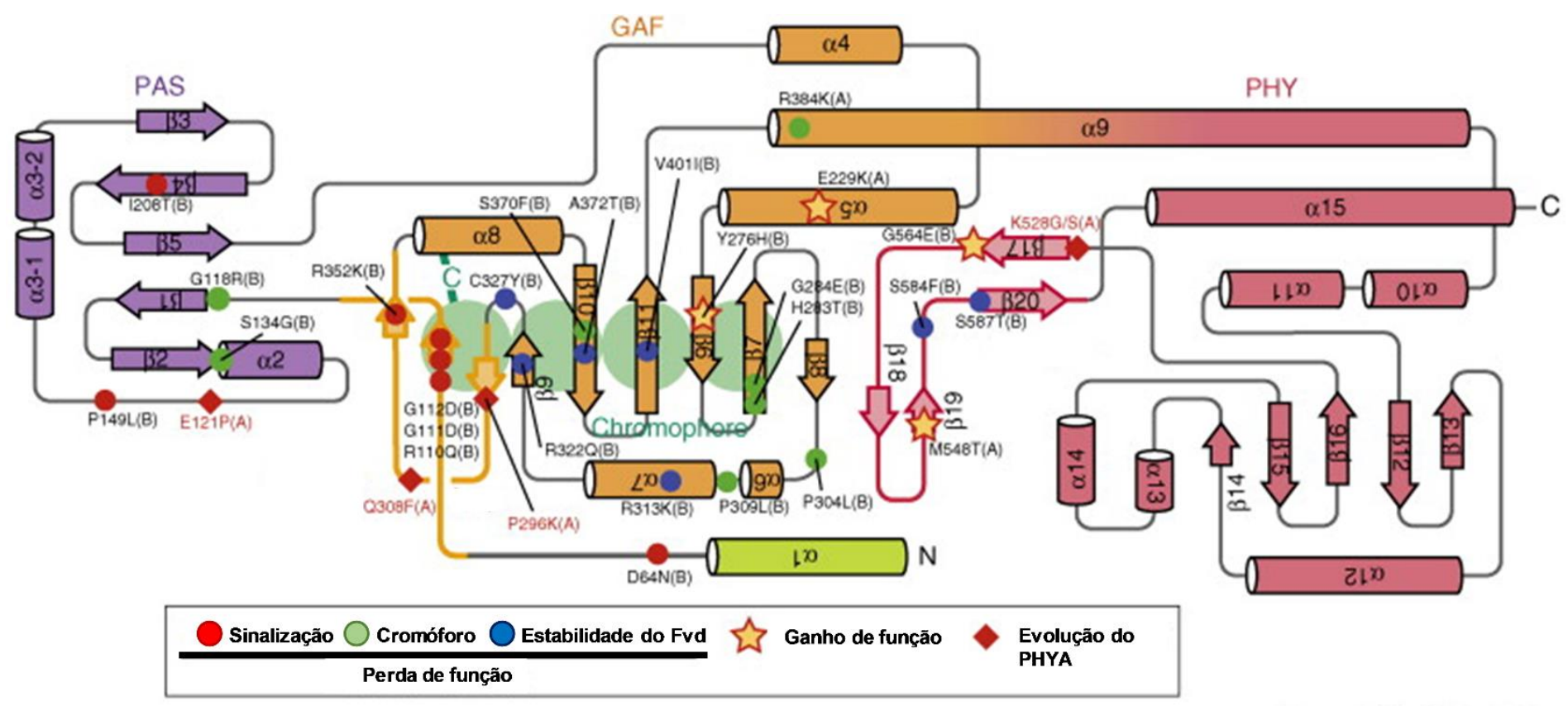


Figura R3. Mutações mapeadas no domínio fotossensor dos fitocromos de Arabidopsis. Mutações de perda de função são classificadas na deficiência da transdução do sinal luminoso (em vermelho), incorporação do cromóforo (em verde) e estabilização do Fvd (em azul). Mutações de ganho de função estão representadas por estrelas. Substituições de aminoácidos importantes para a diversificação das isoformas dos fitocromos estão indicadas por losangos vermelhos. As posições dos aminoácidos estão enumeradas de acordo com PHYA (A) ou PHYB (B). Traduzido de Nagatani (2010).

O resíduo $\mathrm{Y}^{276}$ do $\mathrm{PHYB}$ de Arabidopsis provavelmente interage diretamente com o anel D tetrapirrólico do cromóforo, responsável pela alteração conformacional desencadeadora do sinal e, dessa forma, a proteína mutante $\mathrm{PHYB}^{\mathrm{Y} 276 \mathrm{H}}$ é translocada para o núcleo mesmo na ausência de luz (Oka et al., 2011; Su \& Lagarias, 2007). O perfil transcricional de plântulas de Arabidopsis portadoras de $\mathrm{PHYB}^{\mathrm{Y} 276 \mathrm{H}}$ crescidas no escuro é bastante semelhante ao daquelas crescidas sob luz vermelha contínua, apresentando também um fenótipo de desestiolamento parcial (Hu et al., 2009). Atualmente, alelos de $\mathrm{PHYB}^{\mathrm{Y} 276 \mathrm{H}}$ têm sido empregados no desenvolvimento de novos marcadores moleculares para seleção de linhagens transgênicas devido à intensa autofluorescência na faixa do vermelho da proteína mutante, possibilitando monitoramento não-invasivo de sua expressão, substituindo métodos dependentes de antibióticos ou agrotóxicos (Hu \& Lagarias, 2017). Mutações semelhantes de ganho de função em resíduos de tirosina dos fitocromos também foram verificados em aveia (Jeong et al., 2016), indicando possivelmente respostas conservadas entre os vegetais.

A influência da luz e do fitocromo na síntese de metabólitos de valor nutricional em frutos de tomateiro

Através da modulação da expressão gênica, o fitocromo está diretamente relacionado com importantes respostas fisiológicas durante o ciclo vegetal, como a fotossíntese, a carotenogênese e desenvolvimento de frutos. A manipulação da expressão de genes que codificam as proteínas do fitocromo, bem como a modulação de sua atividade por meio de introdução de mutações, constituem estratégias promissoras para o desenvolvimento de culturas com características 
agronômicas de interesse melhoradas (Boccalandro et al., 2003; Ganesan et al., 2017; Garg et al., 2006; Gupta et al., 2014; Gururani et al., 2015; Thiele et al., 1999; Zhang et al., 2013).

Para o tomateiro, estudos pioneiros identificaram que fitocromos estariam envolvidos no controle da síntese de pigmentos, modulando tanto o acúmulo de carotenoides quanto de flavonoides (Khudairi \& Arboleda, 1971; Piringer \& Heinze, 1954). Plantas de tomateiro sobre-expressando o gene PHYA de aveia apresentaram folhas e frutos verde-escuros, entretanto, nenhuma caracterização metabólica foi realizada nessas linhagens transgênicas (Boylan \& Quail, 1989). Alba et al. (2000) constataram que os níveis de transcritos de PHYA apresentam aumentos consideráveis durante a maturação de frutos de tomateiro na presença de luz e que, de forma interessante, um breve pulso de luz vermelha era capaz de dobrar os teores de licopeno em frutos de tomate mantidos no escuro. A sobreexpressão constitutiva de PHYB1 e PHYB2 em tomateiro levou à inibição do alongamento caulinar e a um acúmulo quase três vezes maior de antocianinas nos tecidos vegetativos (Husaineid et al., 2007), mas nenhuma análise dos impactos dessas manipulações foi realizada no processo de amadurecimento ou sobre a qualidade nutricional dos frutos. Através de estudos realizados com mutantes deficientes em fitocromos específicos, Gupta et al. (2014) indicaram que PHYA possui papel no acúmulo de clorofilas nos frutos e, juntamente com PHYB1, atuam inibindo o acúmulo de licopeno durante o estágio de crescimento do fruto. Os autores afirmam ainda que os diferentes fitocromos atuam de forma a estabelecer um equilíbrio dinâmico entre as fases de maturação do fruto e o controle da síntese e acúmulo de carotenoides nesse órgão. Ademais, o silenciamento frutoespecífico de PHYA e PHYB2 em tomateiro levou à redução no conteúdo de carotenoides totais em frutos maduros em virtude de alterações diretas nos níveis de transcritos de enzimas relacionadas à carotenogênese (Bianchetti et al., 2018).

As proteínas PIFs também influenciam no acúmulo de fitonutrientes. Em tomateiro, Llorente et al. (2016) demonstrou que a biossíntese de carotenoides é reprimida por PIFla devido à sua ligação ao promotor da PHYTOENE SYNTHASE $1(P S Y)$, enzima que atua na etapa inicial da rota carotenogênica, inibindo a sua 
expressão. Os autores ainda verificaram que o silenciamento de PIFla aumenta significativamente o conteúdo de carotenoides totais em frutos maduros. Gramegna et al. (2018) verificou que PIF3 inibe a expressão de GERANYLGERANYL DIPHOSPHATE REDUCTASE (GGDR), responsável pela síntese do precursor dos tocoferóis. Dessa forma, impactos relacionados ao acúmulo de compostos nutracêuticos pelos PHYs podem ser resultado da sua interação com as proteínas PIFs.

Uma das evidências mais marcantes da influência da luz sobre a qualidade nutricional do tomate originou-se do isolamento dos mutantes carregando as mutações monogênicas recessivas high pigment 1 e 2 ( $h p 1$ e hp2), as quais conferem respostas exageradas à luz. Entre outras peculiaridades, tais mutantes são classicamente caracterizados por apresentarem hipocótilos encurtados e altos níveis de antocianinas em suas plântulas, bem como uma pigmentação mais escura em folhas e frutos (Bino et al., 2005; Lieberman et al., 2004). De modo interessante, a pigmentação aumentada nos frutos desses mutantes origina-se de um aumento significativo no número de cloroplastos e nos teores de clorofilas em frutos imaturos, bem como numa maior abundância de cromoplastos e elevação no conteúdo de carotenoides, especialmente licopeno, em frutos maduros. Devido ao aumento em seu conteúdo de licopeno, as mutações $h p$ têm sido introgredidas em várias cultivares de tomateiro, recebendo a denominação geral "Lycopen Rich Tomatoes (LRT)", as quais tem sido utilizadas na extração industrial de licopeno para uso como complemento nutricional de alimentos processados, corantes alimentícios, bem como na indústria de cosméticos e farmacêutica (Levin et al., 2006).

Proposições iniciais sugeriam que as mutações $h p 1$ e $h p 2$ seriam lesões nas estruturas de genes da via biossintética dos carotenoides (Kerckhoffs et al., 1997), todavia, posteriormente demonstrou-se que algumas delas representam diferentes mutações em genes que codificam os ortólogos em tomate dos genes DEETIOLATED1 (DET) e UV DAMAGE DNA BINDING PROTEIN 1 (DDB1) de $A$. thaliana, respectivamente, os quais interagem genética e bioquimicamente e atuam como reguladores negativos da fotomorfogênese (Liu et al., 2004; Mustilli 
et al., 1999). Para validar esses resultados genéticos e estudar a importância funcional de DET1 e DDB1 em tomate, plantas transgênicas com alterações na expressão desses genes foram produzidas, permitindo confirmar que a redução na expressão desses elementos promove aumentos significativos nos teores de clorofilas em frutos imaturos e de carotenoides, flavonoides, tocoferóis (vitamina E), ascorbato (vitamina C) e outros fitonutrientes em frutos maduros (Bino et al., 2005; Cruz et al., 2018; Davuluri et al., 2004; Davuluri et al., 2005; Wang et al., 2008).

A repressão dos transcritos de reguladores negativos da transdução do sinal luminoso em tomate, como CULLIN 4 (CUL4) e COP1, igualmente resultaram no acúmulo de carotenoides e flavonoides (Liu et al., 2004; Wang et al., 2008). Em contrapartida, a supressão constitutiva por RNAi de LONG HYPOCOTYL 5 (HY5), um regulador positivo da transdução do sinal luminoso, reduziu os teores de clorofilas e a formação de tilacóides nos cloroplastos de frutos imaturos, bem como diminuiu o conteúdo de carotenoides totais em frutos maduros (Liu et al., 2004). Portanto, baseado nesses resultados pode-se concluir que ao contrário de COP1, DET1 e DDB1, a proteína HY5 estimula a biogênese de plastídios e a pigmentação de frutos de tomate, o que corrobora sua atuação como um regulador positivo da transmissão do sinal luminoso em plantas (Gangappa \& Botto, 2016). A atuação das proteínas COP1 e DET1 como repressoras de respostas fotomorfogênicas em plantas se baseia na promoção da degradação, via ubiquitinação, de proteínas que atuam como reguladoras positivas na transdução do sinal luminoso, tais como HY5, sendo que esse mecanismo de degradação póstraducional de fatores promotores da fotomorfogênese tem sido interpretado como um aspecto regulatório chave na cascata de sinalização desencadeada pelos fitocromos (Gyula et al., 2003; Wang \& Wang, 2015).

Como mencionado anteriormente, incrementos no conteúdo de carotenoides em frutos de tomate desencadeados por mutações ou modificações por transgenia em genes relacionados à percepção/transdução do sinal luminoso são quase sempre acompanhados de mudanças conspícuas na abundância, tamanho e/ou ultraestrutura dos plastídios. Grande parte dos estudos sobre a formação de 
plastídios e a diferenciação de cloroplastos em cromoplastos tem sido realizada em tomateiro, uma vez que durante a maturação do fruto carnoso desta espécie desenvolvem-se cromoplastos programados para sintetizar e acumular grandes quantidades de carotenoides, tocoferois e outros fitonutrientes lipofílicos (Egea et al., 2010; Li \& Yuan, 2013).

Ao contrário do observado em linhagens transgênicas com alterações em genes de biossíntese de carotenoides, mutantes e transgênicas com mudanças em genes relacionados à transdução do sinal luminoso (como as mutações $h p$ ) são caracterizadas não apenas por aumentos nos fluxos das rotas biossintéticas de compostos nutracêuticos, mas também apresentam incrementos significativos na capacidade de síntese e estocagem dessas substâncias em seus frutos (Azari et al., 2010b; Cookson et al., 2003; Liu et al., 2004). Essa constatação corrobora o atual entendimento de que um dos fatores limitantes ao aumento no conteúdo de fitonutrientes em frutos carnosos consiste em restrições na capacidade de produção e armazenamento dos mesmos e, portanto, esforços devem ser canalizados para a geração de frutos com plastídios maiores, mais abundantes e com estrutura interna mais favorável ao acúmulo desses compostos (Azari et al., 2010b; Cocaliadis et al., 2014; Kolotilin et al., 2007; Wang et al., 2008).

Diante desse cenário, faz-se necessário aquilatar o conhecimento atual acerca do modo pelo qual o sinal luminoso controla a biogênese plastidial, especialmente no que tange ao papel de fotorreceptores como fitocromos durante a formação dessa organela.

Dada a importância central dos fitocromos na cadeia de transdução dos sinais luminosos e seus consequentes impactos na regulação da biossíntese de vários compostos de valor nutricional, parece-nos plausível hipotetizar que alterações quantitativas advindas da sobre-expressão dos genes de fitocromos bem como da modulação de sua ativação por luz especificamente nos tecidos do fruto alterariam os processos de produção e acúmulo de fitonutrientes, gerando tomates com maior conteúdo de compostos nutracêuticos de importância para a saúde humana, como carotenoides, tocoferóis, vitamina $C$ e flavonoides, sem afetar o desenvolvimento vegetativo das plantas. 


\section{Referências}

Alba R, Cordonnier-Pratt M-M, Pratt LH (2000) Fruit-localized phytochromes regulate lycopene accumulation independently of ethylene production in tomato. Plant Physiology 123: 363-370.

Azari R, Tadmor Y, Meir A, Reuveni M, Evenor D, Nahon S, Shlomo H, Chen L, Levin I (2010a) Light signaling genes and their manipulation towards modulation of phytonutrient content in tomato fruits. Biotechnology Advances 28: 108-118.

Azari R, Reuveni M, Evenor D, Nahon S, Shlomo H, Chen L, Levin I (2010b) Overexpression of UV-DAMAGED DNA BINDING PROTEIN 1 links plant development and phytonutrient accumulation in high-pigment-1 tomato. Journal of Experimental Botany 61: 3627-3637.

Bae G, Choi G (2008) Decoding of light signals by plant phytochromes and their interacting factors. Annual Review of Plant Biology 59: 281-311.

Bergougnoux V (2014) The history of tomato: from domestication to biopharming. Biotechnology Advances 32: 170-189.

Bianchetti RE, Lira BS, Monteiro SS, Demarco D, Purgatto E, Rothan C, Rossi M, Freschi L (2018) Fruit-localized phytochromes regulate plastid biogenesis, starch synthesis, and carotenoid metabolism in tomato. Journal of Experimental Botany 69: 3573-3586.

Bino RJ, Ric de Vos CH, Lieberman M, Hall RD, Bovy A, Jonker HH, Tikunov Y, Lommen A, Moco S, Levin I (2005) The light-hyperresponsive high-pigment2dg mutation of tomato: alterations in the fruit metabolome. New Phytologist 166: 427-438.

Boccalandro HE, Ploschuk EL, Yanovsky MJ, Sánchez RA, Gatz C, Casal JJ (2003) Increased phytochrome B alleviates density effects on tuber yield of field potato crops. Plant Physiology 133: 1539-1546.

Borthwick HA (1957) Light effects on tree growth and seed germinaton. Ohio Journal of Science 57: 357-364. 
Borthwick HA, Hendricks SB (1960) Photoperiodism in plants: growth is controlled by light and the measurement of night length through reversible reactions of a pigment. Science 132: 1223-1228.

Borthwick HA, Hendricks SB, Parker MW, Toole EH, Toole VK (1952) A reversible photoreaction controlling seed germination. Proceedings of the National Academy of Sciences 38: 662-666.

Borthwick HA, Hendricks SB, Toole EH, Toole VK (1954) Action of light on lettuce seed germination. Botanical Gazette 115: 205-225.

Bovy A, De Vos R, Kemper M, Schijlen E, Pertejo MA, Muir S, Collins G, Robinson S, Verhoeyen M, Hughes S, Santos-Buelga C, Van Tunen A (2002) Highflavonol tomatoes resulting from the heterologous expression of the maize transcription factor genes LC and C1. Plant Cel/14: 2509-2526.

Bovy A, Schijlen E, Hall RD (2007) Metabolic engineering of flavonoids in tomato (Solanum lycopersicum): the potential for metabolomics. Metabolomics 3: 399-412.

Boylan MT, Quail PH (1989) Oat phytochrome is biologically active in transgenic tomatoes. Plant Cel/1: 765-773.

Burgie ES, Bussell An, Lye SH, Wang T, Hu W, McLoughlin KE, Weber EL, Li $H$, Vierstra RD (2017) Photosensing and thermosensing by phytochrome $B$ require both proximal and distal allosteric features within the dimeric photoreceptor. Scientific Reports 7: 13648.

Burgie ES, Bussell AN, Walker JM, Dubiel K, Vierstra RD (2014) Crystal structure of the photosensing module from a red/far-red light-absorbing plant phytochrome. Proceedings of the National Academy of Sciences USA 111: 1017910184.

Butelli E, Titta L, Giorgio M, Mock H-P, Matros A, Peterek S, Schijlen EGWM, Hall RD, Bovy AG, Luo J, Martin C (2008) Enrichment of tomato fruit with healthpromoting anthocyanins by expression of select transcription factors. Nature Biotechnology 26: 1301-1308. 
Butler WL, Norris KH, Siegelman HW, Hendricks SB (1959) Detection, assay and preliminary purification of the pigment controlling photoresponsive development of plants. Proceedings of the National Academy of Sciences USA 45: 703-708.

Chen M, Tao Y, Lim J, Shaw A, Chory J (2005) Regulation of phytochrome B nuclear localization through light-dependent unmasking of nuclear-localization signals. Current Biology 15: 637-642.

Clack T, Mathews S, Sharrock RA (1994) The phytochrome apoprotein family in Arabidopsis is encoded by five genes: the sequences and expression of PHYD and PHYE. Plant Molecular Biology 25: 413-427.

Cookson PJ, Kiano JW, Shipton CA, Fraser PD, Romer S, Schuch W, Bramley PM, Pyke KA (2003) Increases in cell elongation, plastid compartment size and phytoene synthase activity underlie the phenotype of the high pigment-1 mutant of tomato. Planta 217: 896-903.

Cruz AB, Bianchetti RE, Alves FRR, Purgatto E, Peres LEP, Rossi M, Freschi L (2018) Light, ethylene and auxin signaling interaction regulates carotenoid biosynthesis during tomato fruit ripening. Frontiers in Plant Science 9: 1370.

Davuluri GR, Van Tuinen A, Fraser PD, Manfredonia A, Newman R, Burgess D, Brummell DA, King SR, Palys J, Uhlig J, Bramley PM, Pennings HMJ, Bowler C (2005) Fruit-specific RNAi-mediated suppression of DET1 enhances carotenoid and flavonoid content in tomatoes. Nature Biotechnology 23: 890-895.

Davuluri GR, Van Tuinen A, Mustilli AC, Manfredonia A, Newman R, Burgess D, Brummell DA, King SR, Palys J, Uhlig J, Pennings HMJ, Bowler C (2004) Manipulation of DET1 expression in tomato results in photomorphogenic phenotypes caused by post-transcriptional gene silencing. Plant Journal 40: 344354.

Dieterle M, Bauer D, Büche C, Krenz M, Schäfer E, Kretsch T (2005) A new type of mutation of phytochrome A causes enhanced light sensitivity and alters the degradation and subcellular partitioning of the photoreceptor. Plant Journal 41: 146-161. 
Dorais M, Ehret DL, Papadopoulos AP (2008) Tomato (Solanum lycopersicum) health componentes: from the seed to the consumer. Phytochemistry Reviews 7: 231-250.

Egea I, Barsan C, Bian W, Purgatto E, Latché A, Chervin C, Bouzayen M, Pech J-C (2010) Chromoplast differentiation: current status and perspectives. Plant \& Cell Physiology 51: 1601-1611.

Fankhauser C \& Chen M (2008) Transposing phytochrome into the nucleus. Trends in Plant Science 13: 596-601.

Fraser PD, Römer S, Kiano JW, Shipton CA, Mills PB, Drake R, Schuch W, Bramley PM (2001) Elevation of carotenoids in tomato by genetic manipulation. Journal of the Science of Food and Agriculture 81: 822-827.

Ganesan M, Lee H-Y, Kim J-I, Song P-S (2017) Development of transgenic crops based on photo-biotechnology. Plant, Cell and Environment 40: 2469-2486.

Gangappa SN, Botto JF (2016) The multifaceted roles of HY5 in plant growth and development. Molecular Plant 9: 1353-1365.

Garg AK, Sawers RJH, Wang H, Kim J-K, Walker JM, Brutnell TP, Parthasarathy MV, Vierstra RD, Wu RJ (2006) Light-regulated overexpression of an Arabidopsis phytochrome $A$ gene in rice alters plant architecture and increases grain yield. Planta 223: 627-636.

Garg M, Sharma N, Sharma S, Kapoor P, Kumar A, Chunduri V, Arora P (2018) Biofortified crops generated by breeding, agronomy, and transgenic approaches are improving lives of millions of people around the world. Frontiers in Nutrition 5: 12.

Gramegna G, Rosado D, Carranza APS, Cruz AB, Simon-Moya M, Llorente B, Rodríguez-Concepción M, Freschi L, Rossi M (2018) PHYTOCHROMEINTERACTING FACTOR 3 mediates light-dependent induction of tocopherol biosynthesis during tomato fruit ripening. Plant, Cell \& Environment 42: 1328-1339. 
Grune T, Lietz G, Palou A, Ross AC, Stahl W, Tang G, Thurnham D, Yin SA, Biesalski HK (2010) Beta-carotene is an important vitamin A source for humans. Journal of Nutrition 140: 2268S-2285S.

Gupta SK, Sharma S, Santisree P, Kilambi HV, Appenroth K, Sreelakshmi Y, Sharma R (2014) Complex and shifting interactions of phytochromes regulate fruit development in tomato. Plant, Cell and Environment 37: 1688-1702.

Gururani MA, Ganesan M, Song P-S (2015) Photo-biotechnology as a tool to improve agronomic traits in crops. Biotechnology Advances 33: 53-63.

Gyula P, Schäfer E, Nagy F (2003) Light perception and signaling in higher plants. Current Opinion in Plant Biology 6: 446-452.

Hauser BA, Cordonnier-Pratt MM, Daniel-Vedele F, Pratt LH (1995) The phytochrome gene family in tomato includes a novel subfamily. Plant Molecular Biology 29: 1143-1155.

Heber D, Lu Q-Y (2002) Overview of mechanisms of action of lycopene. Experimental Biology and Medicine 227: 920-923.

Hiltbrunner A, Tscheuschler A, Viczian A, Kunkel T, Kircher S, Schafer E (2006) FHY1 and FHL act together to mediate nuclear accumulation of the phytochrome A photoreceptor. Plant \& Cell Physiology 47: 1023-1034.

Hoang QTN, Han Y-J, Kim J-I (2019) Plant phytochromes and their phosphorylation. International Journal of Molecular Sciences 20: 3450.

Hu W, Lagarias JC (2017) A tightly regulated genetic selection system with signaling-active alleles of phytochrome B. Plant Physiology 173: 366-375.

Hu W, Su Y-S, Lagarias JC (2009) A light-independent allele of phytochrome $B$ faithfully recapitulates photomorphogenic transcriptional networks. Molecular Plant 2: 166-182.

Hughes J (2010) Phytochrome three-dimensional structures and functions. Biochemical Society Transactions 38: 710-716. 
Husaineid SSH, Kok RA, Schreuder MEL, Hanumappa M, Cordonnier-Pratt M-M, Pratt LH, Van der Plas LHW, Van der Krol AR (2007) Overexpression of homologous phytochrome genes in tomato: exploring the limits of photoperception. Journal of Experimental Botany 58: 615-626.

Jeong A-R, Lee S-S, Han Y-J, Shin A-Y, Baek A, Ahn T, Kim M-G, Kim Y-S, Lee K-W, Nagatani A, Kim J-I (2016) New constitutively active phytochromes exhibit light-independent signaling activity. Plant Physiology 171: 2826-2840.

Jiao Y, Lau OS, Deng XW (2007) Light-regulated transcriptional networks in higher plants. Nature Review Genetics 8: 217-230.

Kerckhoffs LHJ, Sengers MMT, Kendrick RE (1997) Growth analysis of wildtype and photomorphogenic-mutant tomato plants. Physiologia Plantarum 99: 309-315.

Kevei E, Schafer E, Nagy F (2007) Light-regulated nucleo-cytoplasmic partitioning of phytochromes. Journal of Experimental Botany 58: 3113-3124.

Khachik F, Carvalho L, Bernstein PS, Muir GJ, Zhao DY, Katz NB (2002) Chemistry, distribution and metabolism of tomato carotenoids and their impact on human health. Experimental Biology and Medicine 227: 845-851.

Khudairi AK, Aboleda OP (1971) Phytochrome-mediated carotenoid biosynthesis and its influence by plant hormones. Physiologia Plantarum 24: 1822.

Kikis EA, Oka Y, Hudson ME, Nagatani A, Quail PH (2009) Residues clustered in the light-sensing knot of phytochrome $B$ are necessary for conformer-specific binding to signaling partner PIF3. PLOS Genetics5: e1000352.

Klose C, Venezia F, Hussong A, Kircher S, Schafer E, Fleck C (2015) Systematic analysis of how phytochrome B dimerization determines its specificity. Nature Plants 1: 15090.

Kolotilin I, Koltai H, Tadmor Y, Bar-Or C, Reuveni M, Meir A, Nahon S, Shlomo H, Chen L, Levin I (2007) Transcriptional profiling of high pigment-2dg 
tomato mutant links early fruit plastid biogenesis with its overproduction of phytonutrients. Plant Physiology 145: 389-401.

Leivar P, Monte E (2014) PIFs: systems integrators in plant development. Plant Cel/26: 56-78.

Leivar P, Quail PH (2011) PIFs: pivotal componentes in a cellular signaling hub. Trends in Plant Science 16: 19-28.

Levin I, Ric de Vos CH, Tadmor Y, Bovy A, Lieberman M, Oren-Shamir M, Segev O, Kolotilin I, Keller M, Ovadia R, Meir A, Bino RJ (2006) High pigment tomato mutants - more than just lycopene (a review). Israel Journal of Plant Sciences 54: 179-190.

Li L, Lagarias JC (1992) Phytochrome assembly: defining chromophore structural requirements for covalent attachment and photoreversibility. Journal of Biological Chemistry 267: 19204-19210.

Li L, Yuan H (2013) Chromoplast biogenesis and carotenoid accumulation. Archives of Biochemistry and Biophysics 539: 102-109.

Li X, Ye J, Munir S, Yang T, Chen W, Liu G, Zheng W, Zhang Y (2019) Biosynthetic gene pyramiding leads to ascorbate accumulation with enhanced oxidative stress tolerance in tomato. International Journal of Molecular Sciences 20: 1558.

Lieberman M, Segev O, Gilboa N, Lalazar A, Levin I (2004) The tomato homolog of the gene encoding UV-damaged DNA binding protein 1 (DDB1) underlined as the gene that causes the high pigment-1 mutant phenotype. Theoretical and Applied Genetics 108: 1574-1581.

Liu Y, Roof S, Ye Z, Barry C, Van Tuinen A, Vrebalov J, Bowler C, Giovannoni $J(2004)$ Manipulation of light signal transduction as a means of modifying fruit nutritional quality in tomato. Proceedings of the National Academy of Sciences USA 26: 9897-9902.

Llorente B, D'Andrea L, Ruiz-Sola MA, Botterweg E, Pulido P, Andilla J, Loza-Alvarez P, Rodríguez-Concepción M (2016) Tomato fruit carotenoid 
biosynthesis is adjusted to actual ripening progression by a light-dependent mechanism. Plant Journa/85: 107-119.

Lu XD, Zhou CM, Xu PB, Luo Q, Lian HL, Yang HQ (2015) Red-lightdependent interaction of phyB with SPA1 promotes COP1-SPA1 dissociation and photomorphogenic development in Arabidopsis. Molecular Plant 8: 467-478.

Martin C, Butelli E, Petroni K, Tonelli C (2011) How can research on plants contribute to promoting human health? Plant Cel/23: 1685-1699.

Muir SR, Collins GJ, Robinson S, Hughes S, Bovy A, Ric De Vos $\mathrm{CH}$, Van Tunen AJ, Verhoeyen ME. 2001. Overexpression of petunia chalcone isomerase in tomato results in fruit containing increased levels of flavonols. Nature Biotechnology 19: 470-474.

Mustilli AC, Fenzi F, Ciliento R, Alfano F, Bowler C (1999) Phenotype of the tomato high pigment- 2 mutant is caused by a mutation in the tomato homolog of DEETIOLATED1. Plant Cel/11: 145-157.

Nagatani A (2010) Phytochrome: structural basis for its functions. Current Opinion in Plant Biology 13: 565-570.

Oka Y, Kong S-G, Matsushita T (2011) A non-covalently attached chromophore can mediate phytochrome B signaling in Arabidopsis. Plant \& Cell Physiology 52: 2088-2102.

Pfeiffer A, Nagel MK, Popp C, Wust F, Bindics J, Viczian A, Hiltbrunner A, Nagy F, Kunkel T, Schafer E (2012) Interaction with plant transcription factors can mediate nuclear import of phytochrome B. Proceedings of the National Academy of Sciences USA 109: 5892-5897.

Pham VN, Kathare PK, Huq E (2018) Phytochromes and phytochrome interacting factors. Plant Physiology 176: 1025-1038.

Pickart CM (2001) Mechanisms underlying ubiquitination. Annual Reviews of Biochemistry 70: 503-533.

Piringer AA, Heinze PH (1954) Effect of light on the formation of a pigment in the tomato fruit cuticle. Plant Physiology 29: 467-472. 
Podolec R, Ulm R (2018) Photoreceptor-mediated regulation of the COP1/SPA E3 ubiquitin ligase. Current Opinion in Plant Biology 45: 18-25.

Qiu Y, Pasoreck EK, Reddy AK, Nagatani A, Ma W, Chory J, Chen M (2017) Mechanism of early light signaling by the carboxy-terminal output module of Arabidopsis phytochrome B. Nature Communications 8: 1905.

Quail PH (2002) Phytochrome photosensory signaling networks. Nature Reviews Molecular Cell Biology 3: 85-93.

Rockwell NC, Su Y-S, Lagarias JC (2006) Phytochrome structure and signaling mechanisms. Annual Review of Plant Biology 57: 837-858.

Römer S, Fraser PD, Kiano JW, Shipton CA, Misawa N, Schuch W, Bramley PM (2000) Elevation of the provitamin A content of transgenic tomato plants. Nature Biotechnology 18: 666-669.

Sharrock RA, Quail PH (1989) Novel phytochrome sequences in Arabidopsis thaliana: structure, evolution and differential expression of a plant regulatory photoreceptor family. Genes and Development 3: 1745-1757.

Shen H, Zhu L, Castillon A, Majee M, Downie B, Huq E (2008) Light-induced phosphorylation and degradation of the negative regulator PHYTOCHROMEINTERACTING FACTOR 1 from Arabidopsis depend upon its direct physical interactions with photoactivated phytochromes. Plant Cel/20: 1586-1602.

Stice CP, Xia H, Wang X-D (2018) Tomato lycopene prevention of alcoholic fatty liver disease and hepatocellular carcinoma development. Chronic Diseases and Translational Medicine 4: 211-224.

Su Y-S, Lagarias JC (2007) Light-independent phytochrome signaling mediated by dominant GAF domain tyrosine mutants of Arabidopsis phytochromes in transgenic plants. Plant Cel/19: 2124-2139.

Thiele A, Herold M, Lenk I, Quail PH, Gatz C (1999) Heterologous expression of Arabidopsis phytochrome $B$ in transgenic potato influences photosynthetic performance and tuber development. Plant Physiology 120: 73-81. 
Von Horsten S, Strass S, Hellwig N, Gruth V, Klasen R, Mielcarek A, Linne U, Morgner N, Essen LO (2016) Mapping light-driven conformational changes within the photosensory module of plant phytochrome B. Scientific Reports 6: 34366.

Wagner JR, Brunzelle JS, Forest KT, Vierstra RD (2005) A light-sensing knot revealed by the structure of the chromophore-binding domain of phytochrome. Nature 438: 325-331.

Wang $\mathrm{H}$, Wang $\mathrm{H}$ (2015) Phytochrome signaling: time to tighten up the loose ends. Molecular Plant 8: 540-551.

Wang S, Liu J, Feng Y, Niu X, Giovannoni J, Liu Y (2008) Altered plastid levels and potential for improved fruit nutrient content by downregulation of the tomato DDB1-interacting protein CUL4. Plant Journal 55: 89-103.

West CE, Eilander A, Van Lieshout M (2002) Consequences of revised estimates of carotenoid bioefficacy for dietary control of vitamin A deficiency in developing countries. Journal of Nutrition 132: 2920S-2926S.

Wilson DW, Nash P, Buttar HS, Griffiths K, Singh R, De Meester F, Horiuchi R, Takahashi T (2017) The role of food antioxidants, benefits of functional foods, and influence of feeding habits on the health of the older person: an overview. Antioxidants 6: 81.

Xu W, Dubos C, Lepiniec L (2015a) Transcriptional control of flavonoid biosynthesis by MYB-bHLH-WDR complexes. Trends in Plant Science 20: 176-185.

Xu X, Paik I, Zhu L, Huq E (2015b) Illuminating progress in phytochromemediated light signaling pathways. Trends in Plant Science 20: 641-650.

Yang Y, Linke M, Von Haimberger T, Matute R, González L, Schmieder P, Heyne K (2014) Active and silent chromophore isoforms for phytochrome $\mathrm{Pr}$ photoisomerization: an alternative evolutionary strategy to optimize photoreaction quantum yields. Structural Dynamics 1: 014701.

Zhang J, Stankey RJ, Vierstra RD (2013) Structure-guided engineering of plant phytochrome B with altered photochemistry and light signaling. Plant Physiology 161: 1445-1457. 
Ziegler T, Möglich A (2015) Photoreceptor engineering. Frontiers in Molecular Biosciences 2: 30. 


\section{OBJETIVOS}

A presente tese tem como objetivo principal investigar os impactos da manipulação dos níveis de fitocromos bem como de sua atividade como estratégia para a biofortificação de frutos do tomateiro.

De forma específica, empregamos uma abordagem fruto-específica para a sobre-expressão da forma nativa do FITOCROMO B2 (PHYB2) e da forma mutada $\mathrm{PHYB2}^{\mathrm{Y} 252 \mathrm{H}}$ (constitutivamente ativa independente do sinal luminoso) e avaliamos os impactos de ambas manipulações especialmente sobre o perfil global de transcritos, biogênese dos plastídios e acúmulo de compostos de valor nutricional durante o desenvolvimento e amadurecimento dos frutos de tomateiro. 

O conhecimento dos mecanismos moleculares, bioquímicos e fisiológicos pelos quais as plantas respondem aos sinais luminosos nos permite identificar possíveis alvos de manipulação biotecnológica visando especialmente a modificação de traços agronômicos de interesse, tanto para facilitação do cultivo e colheita quanto para a melhoria da saúde e nutrição humana. Nesse sentido, os resultados obtidos pela presente tese contribuem com a demonstração de que a manipulação da atividade de fotorreceptores consiste numa interessante estratégia biotecnológica para a biofortificação de frutos.

Através da sobre-expressão fruto-específica da forma nativa do fotorreceptor de luz vermelha/vermelha-distante PHYB2 e de uma forma mutada constitutivamente ativa $P H Y B 2^{Y 252 H}$ em tomateiro, verificamos aumentos significativos em diversas classes de compostos bioativos considerados antioxidantes benéficos para a saúde humana, como carotenoides, flavonoides e vitaminas $\mathrm{C}$ e $\mathrm{E}$. Entre os resultados mais interessantes, comprovamos pela primeira vez que a manipulação da atividade dos fotorreceptores é uma estratégia fotobiotecnológica para a biofortificação de frutos carnosos, uma vez que o acúmulo de antioxidantes foi significativamente intensificado pela sobreexpressão de PHYB2 ${ }^{\mathrm{Y} 252 \mathrm{H}}$ em comparação à forma nativa do fotorreceptor.

Grande parte dos impactos positivos observados puderam ser explicados pela influência de PHYB2 e PHYB2 ${ }^{\mathrm{Y} 252 \mathrm{H}}$ sobre o desenvolvimento de plastídios, organelas relacionadas com a síntese e a capacidade de armazenamento de vários compostos bioativos, e sobre a modulação diferencial de genes envolvidos com a biossíntese de antioxidantes.

A mutação resultante da ativação constitutiva independente de luz do fitocromo foi originalmente observada em PHYB de Arabidopsis thaliana e, nesta tese, constatamos que a mesma estratégia pôde ser utilizada em outra espécie como o tomateiro, uma vez que a estrutura e a função de diversos elementos da cadeia de transdução do sinal luminoso é conservada entre os vegetais. Dessa forma, 
hipotetizamos que a modulação da atividade dos fotorreceptores como estratégia para biofortificação pode ser aplicada com sucesso em outros frutos carnosos.

Algumas novas interessantes perguntas podem ser formuladas a partir dos achados registrados nesta tese. Como se dá a interação do fitocromo constitutivamente ativo com seus fatores intermediários bem como o seu turnover ao nível de proteína? Seria possível potencializar os efeitos observados pela introdução de novas mutações de ganho-de-função além da $\mathrm{Tyr}^{252}$-para-His ou pela combinação de outros fitocromos mutados para ganho-de-função? Qual seria o limite de capacidade de estocagem de compostos bioativos no fruto através da modulação fruto-específica? Como se comportaria o fruto transgênico fora da planta mãe em condições de pós-colheita? Quais seriam os impactos da incorporação da mutação Tyr ${ }^{252}$-para-His via estratégias de edição genômica (e.g., sistema CRISPR-Cas9) sobre o desenvolvimento e produtividade da planta, bem como sobre a qualidade dos frutos?

Espero, ainda, que a presente tese tenha contribuído para ressaltar a importância de investimentos para a Educação, Ciência e Tecnologia brasileiras, uma vez que todos os resultados e avanços científicos aqui apresentados somente foram possíveis graças ao apoio financeiro e suporte institucional de órgãos públicos. 


\section{PRODUÇÃO CIENTÍFICA E ACADÊMICA NO PERÍODO}

Co-autoria em artigos completos publicados em periódicos

Lira BS, Gramegna G, Trench BA, Alves FRR, Silva EM, Silva GFF, Thirumalaikumar VP, Lupi ACD, Demarco D, Purgatto E, Nogueira FTS, Balazadeh S, Freschi L, Rossi M (2017) Manipulation of a senescence-associated gene improves fleshy fruit yield. Plant Physiology 175: 77-91.

Pikart FC, Marabesi MA, Mioto PT, Gonçalves AZ, Matiz A, Alves FRR, Mercier H, Aidar MPM (2018) The contribution of weak CAM to the photosynthetic metabolic activities of a bromeliad species under water deficit. Plant Physiology and Biochemistry 123: 297-303.

Cruz AB, Bianchetti RE, Alves FRR, Purgatto E, Peres LEP, Rossi M, Freschi L (2018) Light, ethylene and auxin signaling interaction regulates carotenoid biosynthesis during tomato fruit ripening. Frontiers in Plant Science 9: 1370.

Lupi ACD, Lira BS, Gramegna G, Trench B, Alves FRR, Demarco D, Peres LEP, Purgatto E, Freschi L, Rossi M (2019) Solanum lycopersicum GOLDEN 2-LIKE 2 transcription factor affects fruit quality in a light- and auxin-dependent manner. PLOS ONE 14: e0212224.

Crispim-Filho AJ, Costa AC, Alves FRR, Batista PF, Rodrigues AA, VasconcelosFilho SC, Nascimento KJT (2019) Deficiency in phytochromobilin biosynthesis enhances heat-stress-induced impairments to the photosynthetic apparatus in tomato. Biologia Plantarum 63: 134-143.

Rosado D, Trench B, Bianchetti R, Zuccarelli R, Alves FRR, Purgatto E, Floh EIS, Nogueira FTS, Freschi L, Rossi M (2019) Downregulation of tomato PHYTOCHROME-INTERACTING FACTOR 4 impacts plant development and fruit production. Plant Physiology. (in press). 
Capítulos de livros publicados

Alves FRR, Pikart FC (2019) Introdução à fotobiologia em plantas: luz, fotossíntese e fotorreceptores. In: Lozano et al. (org.) IX Botânica no Inverno 2019. p. 160-170. ISBN 978-85-85658-80-9.

Bianchetti RE, Alves FRR, Freschi L (2019) Interações entre fitocromos e hormônios vegetais. In: Carvalho et al. (org.) Fitocromos: moléculas fantásticas na vida das plantas. (in press).

Organização de eventos

Silva FN, Alves FRR, Ferrari RC, Gobara BNK, Sacramento GN, Rosado D, Maximo EP, Silva LNNS, Martins NT, Della AP, Cabral A. VIII Botânica no Inverno. 2018. 